\title{
Platelets Control Leukocyte Recruitment in a Murine Model of Cutaneous Arthus Reaction
}

\author{
Toshihide Hara, ${ }^{*}$ Kazuhiro Shimizu, ${ }^{*}$ \\ Fumihide Ogawa, ${ }^{*}$ Koichi Yanaba, ${ }^{*}$ Yohei Iwata, ${ }^{*}$ \\ Eiji Muroi, ${ }^{*}$ Motoi Takenaka, ${ }^{*}$ Kazuhiro Komura, ${ }^{\dagger}$ \\ Minoru Hasegawa, ${ }^{\dagger}$ Manabu Fujimoto, ${ }^{\dagger}$ \\ and Shinichi Sato*

\begin{abstract}
From the Department of Dermatology," Nagasaki University Graduate School of Biomedical Sciences, Nagasaki, and the Department of Dermatology, ${ }^{\dagger}$ Kanazawa University Graduate School of Medical Science, Kanazawa, Japan
\end{abstract}

Platelets have been shown to be important in inflammation, but their role in the cutaneous Arthus reaction remains unclear. To assess the role of platelets in this pathogenetic process, the cutaneous Arthus reaction was examined in wild-type mice and mice lacking E-selectin, P-selectin, or P-selectin glycoprotein ligand-1 (PSGL-1) with or without platelet depletion by busulfan, a bone marrow precursor cell-specific toxin. Edema and hemorrhage induced by immune complex challenge significantly decreased in busulfan-treated wild-type mice compared with untreated mice. Busulfan treatment did not affect edema and hemorrhage in P-selectin- or PSGL-1-deficient mice, suggesting that the effect by busulfan is dependent on P-selectin and PSGL-1 expression. The inhibited edema and hemorrhage paralleled reduced infiltration of neutrophils and mast cells and reduced levels of circulating platelets. Increased cutaneous production of interleukin-6, tumor necrosis factor- $\alpha$, and platelet-derived chemokines during Arthus reaction was inhibited in busulfan-treated wild-type mice relative to untreated mice, which paralleled the reduction in cutaneous inflammation. Flow cytometric analysis showed that immune complex challenge generated blood platelet-leukocyte aggregates that decreased by busulfan treatment. In thrombocytopenic mice, the cutaneous inflammation after immune complex challenge was restored by platelet infusion. These results suggest that platelets induce leukocyte recruitment into skin by forming platelet-leukocyte aggregates and secreting chemokines at inflamed sites, mainly through the interaction of P-selectin on platelets with PSGL-1 on leukocytes. (Am J Pathol 2010, 176:259-269; DOI: 10.2353/ajpath.2010.081117)

The pathogenesis of autoimmune diseases frequently involves the formation of IgG-containing immune complexes (ICs) inducing inflammatory responses with significant tissue injury, commonly referred to as type III hypersensitivity reaction. This IC injury has been implicated in the pathogenesis of vasculitis syndrome, systemic lupus erythematosus, rheumatoid arthritis, and cryoglobulinemia. ${ }^{1}$ The mechanisms by which the immune system controls effector responses to ICs are of central importance for developing therapeutic strategies. The standard animal model for the inflammatory response in these IC-mediated diseases is the Arthus reaction. ${ }^{2}$ Analyses using gene knockout mice have revealed that activation of the complement system, especially $\mathrm{C5a}$ and its interaction with $\mathrm{C} 5 \mathrm{a}$ receptor, and of Fc receptors for IgG on inflammatory cells, particularly mast cells, are both required to initiate the Arthus reaction. ${ }^{3-8}$ In addition, accumulation of neutrophils and mast cells is necessary for the progression of the IC-mediated vascular tissue damage, which results in edema and hemorrhage. ${ }^{3-8}$

Leukocyte recruitment from the circulation to a site of inflammation is an essential process in the inflammatory response. Leukocytes first tether and roll on vascular endothelial cells, before they are activated to adhere firmly and subsequently immigrate into the extravascular space. This multistep process is highly regulated by multiple cell-surface adhesion molecules.9,10 The selectins cooperate to support leukocyte tethering and rolling along inflamed vascular walls by mediating leukocyte interactions with glycoconjugated counter-receptors expressed by endothelium, adherent platelets, or leukocytes. The selectin family consists of three cell-surface

Supported by a grant of Research on Intractable Diseases from the Ministry of Health, Labour and Welfare of Japan.

Accepted for publication September 24, 2009

Address reprint requests to Dr. Shinichi Sato, M.D., Ph.D., Department of Dermatology, Nagasaki University Graduate School of Biomedical Sciences, 1-7-1 Sakamoto, Nagasaki 852-8501, Japan. E-mail: s-sato@ nagasaki-u.ac.jp. 
molecules expressed by leukocytes (L-selectin), vascular endothelium (E- and P-selectins), and platelets (P-selectin). ${ }^{11}$ Although the adhesive mechanisms underlying the capture and immobilization of circulating leukocytes in inflamed blood vessels have been well described, factors triggering and controlling the leukocyte recruitment into inflamed sites are poorly understood.

The multistep process of leukocyte tethering and rolling, followed by leukocyte activation and firm adhesion, also occurs on activated platelets. ${ }^{12}$ Platelets are essential for primary hemostasis, but they also play an important proinflammatory role. ${ }^{13,14}$ Platelets normally circulate in a quiescent state, protected from untimely activation by inhibitory mediators released from intact endothelial cells. Endothelial dysfunction and changes in release of antiplatelet factors lead to increased platelet activation followed by their interaction with leukocytes, and increased platelet adhesion and aggregation. ${ }^{15,16}$ On activation, platelets can change their shapes as well as the expression pattern of adhesion molecules, and secrete neutrophil and endothelial activators inducing production of pro-inflammatory cytokines. ${ }^{17}$ These changes are associated with the adhesion of platelets to leukocytes and endothelium. ${ }^{14}$ Thus, platelets are important amplifiers of acute inflammation.

Platelets accumulate in inflammatory lesions concomitantly with leukocytes and regulate a variety of inflammatory responses by secreting or activating adhesion proteins, growth factors, and coagulation factors. ${ }^{18,19}$ These proteins induce widely differing biological activities, including cell adhesion, chemotaxis, cell survival, and proliferation, all of which accelerate the inflammatory process. $^{20}$ In vitro and in vivo studies have shown that platelets bind to leukocytes through their surface protein. ${ }^{12,14,20,21}$ Indeed, previous studies have reported that platelet-leukocyte aggregates are formed in circulating blood of asthmatic patients. ${ }^{22}$ Platelets express much amounts of P-selectin than endothelium and also bind endothelium via selectin dependent and independent mechanisms. ${ }^{23-25}$ In addition to classical leukocyte recruitment process, platelets bound to activated endothelial cells can interact with leukocytes, which results in secondary capture that induces interactions of leukocytes with platelets first, followed by leukocyte-endothelial cell interaction. ${ }^{26}$ Leukocytes within platelet-leukocyte complexes have increased adhesive capacity to the activated endothelium. ${ }^{27}$ Therefore, platelet can function as a bridge between the circulating leukocyte and endothelium.

We previously showed that mice lacking P-selectin $\left(\mathrm{P}\right.$-selectin $\left.{ }^{-1-}\right)$ or mice treated with anti- P-selectin glycoprotein ligand-1 (PSGL-1) antibody (Ab) exhibited reduced Arthus reaction that is associated with decreased infiltration of neutrophils and mast cells. ${ }^{28,29}$ In addition to interacting with selectins and selectin ligands on endothelial cells, leukocytes can also interact with selectins and selectin ligands presented by platelets or their microparticle fragments, which are all found at sites of inflammation. ${ }^{30}$ This indicates that observations of altered leukocyte recruitment in selectin- and selectin ligand-deficient mice must be discussed in light of altered selectin and selectin-ligand expression not only by endo- thelial cells, but also by platelets. Recently, involvement of platelets has been demonstrated in the pathogenesis of inflammatory disorders, including asthma, ${ }^{22,31}$ arthritis, ${ }^{18}$ inflammatory bowel disease, ${ }^{32}$ and chronic allergic dermatitis. ${ }^{33}$ Although the role of platelets in inflammatory process is being increasingly recognized, it remains unknown how platelets induce leukocyte recruitment in the cutaneous Arthus reaction. A recent report has identified a role of platelets in promoting IC-induced leukocyte recruitment to the cremaster muscle in a murine model of reverse passive Arthus reaction. ${ }^{34}$ However, the relative role of each leukocyte and adhesion molecule in the inflammation varies according to the tissue site and the nature of inflammatory stimuli. ${ }^{29}$ Therefore, to clarify the importance of platelets, their surface adhesion molecule expression, and platelet-derived chemokines on leukocyte recruitment, we examined the cutaneous Arthus reaction in wild-type, $\mathrm{P}$-selectin ${ }^{-1-}$, E-selectin ${ }^{-1-}$, and PSGL-1 ${ }^{-1-}$ mice, with or without treatment with busulfan, a bone marrow precursor cell-specific toxin.

\section{Materials and Methods}

\section{Mice}

P-selectin ${ }^{-1-}, 35$ E-selectin ${ }^{-1-}, 35$ PSGL-1 ${ }^{-1-}, 36$ and wildtype C57BL/6 mice were obtained from The Jackson Laboratory (Bar Harbor, ME). All mice were healthy, fertile, and did not display evidence of infection or disease. All mice were backcrossed between 5 and 10 generations onto the C57BL/6 genetic background. Mice used for experiments were 8 to 12 weeks old. Wild-type and P-selectin ${ }^{-1-}$ mice were used at the age of 6 to 8 weeks old for studies of platelet restoration. All mice were housed in a pathogen-free barrier facility and screened regularly for pathogens. All studies and procedures were approved by the Committee on Animal Experimentation of Nagasaki University Graduate School of Biomedical Sciences.

\section{Busulfan-Induced Platelet Depletion}

Busulfan (Sigma-Aldrich, St. Louis, MO), a bone marrow precursor of cell-specific toxin, was used to deplete platelets, as previously described. ${ }^{37}$ Busulfan was prepared in polyethylene glycol $400(25 \mathrm{mg} / \mathrm{ml})$ at room temperature for 1 hour and then heated at $65^{\circ} \mathrm{C}$ to $70^{\circ} \mathrm{C}$ until the mixture went into solution before dilution (1:8) in warm saline for injection. It induces a gradual, long-term, nonimmune thrombocytopenia. Anesthetized mice received $0.2 \mathrm{ml}$ of busulfan $(20 \mathrm{mg} / \mathrm{kg}$ ) or vehicle intraperitoneally on days 0 and 3 .

\section{Platelet and Leukocyte Counts in Blood}

Blood was collected before IC challenge from mice via lateral caudal vein using glass pipettes dipped in 3.8\% sodium citrate solution (Sigma-Aldrich) for platelet and leukocyte enumeration. Blood was smeared onto microscope slides for differential leukocyte counts using the 
DiffQuik method. Platelets were counted using the method of Brecher and Cronkite. ${ }^{38}$

\section{Reverse Passive Arthus Reactions}

For cutaneous reverse passive Arthus reactions, mice anesthetized by inhalation of diethyl ether were shaved on their dorsal skin and wiped with $70 \%$ alcohol. After 14 days from first busulfan treatment, rabbit IgG antichicken egg albumin Abs (60 $\mu \mathrm{g} / 30 \mu \mathrm{l}$; Cappel, Aurora, $\mathrm{OH})$ were injected intradermally with a 29-gauge needle, followed immediately by intravenous injection of chicken egg albumin (20 mg/kg; Sigma-Aldrich). ${ }^{5}$ The intradermal injection of purified polyclonal rabbit IgG $(60 \mu \mathrm{g} / 30 \mu \mathrm{l}$; Sigma-Aldrich) followed by intravenous installation of chicken egg albumin served as a control. The solution of chicken egg albumin contained 1\% Evans blue dye (SigmaAldrich). Tissues were harvested 4 or 8 hours later and assessed for edema, hemorrhage, and numbers of infiltrating neutrophils and mast cells.

\section{Quantitation of Edema and Hemorrhage}

Edema was evaluated by measuring the vascular leak 4 hours after IC challenge. ${ }^{5}$ Mice were sacrificed, and the skin containing the injection site was removed at the level of fascia above skeletal muscle and was reversed. The diameter of extravascular Evans blue dye on the fascia side of the injection site was measured directly. Evans blue dye binds to serum proteins and thereby can be used to quantify alterations in vascular permeability. The diameter of the major and minor axis of the blue spot was averaged for analysis. The amount of hemorrhage was assessed 8 hours after IC challenge by direct macroscopic measurement of the purpuric spot. The diameter of the major and minor axis of the purpuric spot was averaged for analysis.

\section{Histological Examination}

Tissues were harvested 4 or 8 hours after IC challenge using a disposable, sterile, 6-mm punch biopsy (Maruho, Osaka, Japan) and assessed for tissue damage and number of infiltrating neutrophils and mast cells. Tissues were cut into halves, fixed in 3.5\% paraformaldehyde, and then paraffin-embedded. Six-micrometer sections were stained using $\mathrm{H} \& \mathrm{E}$ for neutrophil evaluation and toluidine blue for mast cell staining. Neutrophil and mast cell infiltration was evaluated by counting extravascular neutrophils and mast cells in the entire section and averaging the numbers present in 10 serial skin sections from the injection site. Each section was examined independently by three investigators in a blinded fashion, and the mean was used for analysis.

\section{RNA Isolation and Real-Time PCR}

Total RNAs were extracted from frozen wounded skin samples using Qiagen RNeasy spin columns (QIAGEN,
Crawley, UK) and subsequently were reverse transcribed to cDNA using Ready-To-Go real-time reverse transcriptase (RT)-PCR Beads (GE Health care, Buckinghamshire, UK), according to the manufacturer's protocols. Realtime quantitative RT-PCR was performed using the TaqMan system (Applied Biosystems, Foster City, CA) on ABI Prism 7300 Sequence Detector (Applied Biosystems) according to the manufacturer's instructions. TaqMan probes and primers for interleukin (IL)-6, tumor necrosis factor (TNF)- $\alpha$, platelet factor 4 (PF4)/CXCL4, monocyte chemotactic protein-1 (MCP-1)/CCL2, regulated on activation normal $\mathrm{T}$ expressed and secreted (RANTES)/ CCL5, and glyceraldehyde-3-phosphate dehydrogenase (GAPDH) were purchased from Applied Biosystems. Relative expression of PCR products was determined using the $\Delta \Delta \mathrm{C}_{\mathrm{T}}$ method. Briefly, each set of samples was normalized using the difference in threshold cycle $\left(\mathrm{C}_{\mathrm{T}}\right)$ between the target gene and housekeeping gene (GAPDH): $\Delta \mathrm{C}_{\mathrm{T}}=\left(\mathrm{C}_{\mathrm{T} \text { target gene }}-\mathrm{C}_{\mathrm{T} \text { GAPDH }}\right)$. Relative mRNA levels were calculated by the expression $2^{-} \Delta \Delta C T$, where $\Delta \Delta \mathrm{C}_{\mathrm{T}}=\Delta \mathrm{C}_{\mathrm{T} \text { sample }}-\Delta \mathrm{C}_{\mathrm{T}}$ calibrator. Each sample was examined in duplicate and the mean $\mathrm{C}_{\mathrm{T}}$ was used in the equation. For real-time RT-PCR analysis of growth factor mRNA expression, 5 to 8 mice were used in each group.

\section{Flow Cytometric Analysis}

Blood (50 $\mu$ l) was obtained via retro orbital route before and at 2 and 4 hours after IC challenge and incubated with fluorescein isothiocyanate-labeled rat anti-CD41 (BD Pharmingen, San Diego, CA) Ab and peridinin cholorphyll protein-labeled rat anti-CD45 (BD Pharmingen) or isotype control antibodies within 10 minutes of sampling. After 10 minutes incubation at room temperature, $200 \mu \mathrm{l}$ of FACSlyse solution (BD Pharmingen) was added for a further 10 minutes before the addition of $500 \mathrm{ml}$ of paraformaldehyde (1\% in PBS). These samples were analyzed using Epics XL ADC flow cytometer (Beckman Coulter, Fullerton, CA). Live gating was performed for leukocyte-sized events, the forward and side scattering characteristics of which exclude the presence of single platelet alone as described previously. ${ }^{39}$ Events staining positive for both CD45 and CD41 were considered to represent platelet-leukocyte aggregates and were distinguishable from events staining for CD45 alone.

\section{Isolation of Murine Platelets}

Blood was obtained by means of cardiac puncture from anesthetized mice, mixed with acid citrate dextrose (SigmaAldrich) at a 9:1 ratio, and then centrifuged at $150 \times \mathrm{g}$ for 10 minutes. The platelet-rich plasma obtained was washed using the method of Mustard et al. ${ }^{40}$ Washed platelets were suspended in minimal essential medium (Gibco, Grand Island, NY) containing 300 ng/ml prostaglandin $\mathrm{I}_{2}$ (Sigma-Aldrich) and $10 \%$ fetal calf serum (ICN Biomedicals, Aurora, $\mathrm{OH})$. The cellular content of the suspension was greater than 99\% platelets, as demonstrated by flow cytometry light scattering analysis. Con- 
Table 1. Circulating Blood Cell Numbers in Whole Blood from Wild-Type Mice, Wild-Type Mice Treated with Busulfan (Wild-Type + Busulfan), E-selectin (E-sel) ${ }^{-/-}$Mice, P-selectin (P-sel) ${ }^{-1-}$ Mice, and PSGL-1 ${ }^{-1-}$ Mice Before IC Challenge

\begin{tabular}{lcccrr}
\hline \multicolumn{1}{c}{ Blood cell type } & Wild-type & Wild-type + busulfan & E-sel $^{-1-}$ & P-sel $^{-1-}$ & PSGL-1 \\
\hline Leukocytes $\left(10^{3} / \mu l\right)$ & $9.3 \pm 2.5$ & $8.2 \pm 2.3$ & $6.0 \pm 0.8$ & $7.8 \pm 2.0$ & $9.6 \pm 0.6$ \\
Neutrophils $\left(10^{3} / \mu \mathrm{l}\right)$ & $2.0 \pm 0.7$ & $1.8 \pm 0.6$ & $1.8 \pm 0.4$ & $2.3 \pm 0.8$ & $2.4 \pm 0.4$ \\
Lymphocytes $\left(10^{3} / \mu \mathrm{l}\right)$ & $7.3 \pm 2.3$ & $6.4 \pm 2.0$ & $4.0 \pm 0.8$ & $5.5 \pm 1.7$ & $6.6 \pm 0.2$ \\
Monocytes $\left(10^{2} / \mu \mathrm{l}\right)$ & $1.9 \pm 0.4$ & $1.5 \pm 0.3$ & $1.8 \pm 0.3$ & $1.6 \pm 0.3$ & $2.2 \pm 0.4$ \\
Platelets $\left(10^{5} / \mu \mathrm{l}\right)$ & $6.4 \pm 1.3$ & $3.8 \pm 1.0$ & $8.2 \pm 1.0$ & $9.8 \pm 2.3$ & $10.2 \pm 1.0$ \\
\hline
\end{tabular}

Data are presented as mean \pm SEM of results obtained from 5 to 10 mice in each group.

tamination with leukocytes and erythrocytes represented less than $1 \%$ of the cellular content (data not shown).

\section{Restoration of Platelet Population in Platelet-Depleted Mice}

Washed platelets were isolated from the blood of wildtype and P-selectin ${ }^{-1-}$ mice. The resulting platelet suspension or vehicle was injected intravenously into busulfan-treated wild-type mice 20 minutes before IC challenge. The injection volume of $100 \mu \mathrm{l}$ contained 5.5 to $6.0 \times 10^{8}$ platelets. Platelet reconstitution restored the circulating platelet population to 90 to $95 \%$ of the control level.

\section{Statistical Analysis}

The Mann-Whitney U-test was used for determining the level of significance of differences in sample means and Bonferroni's test was used for multiple comparisons. Spearman's rank correlation coefficient was used to examine the relationship between two continuous variables. A $P$ value less than 0.05 was considered significant.

\section{Results}

\section{Effect of Busulfan Administration on Peripheral Blood Cell Numbers}

To study the role of platelets in cutaneous Arthus reaction, we induced platelet depletion by injection of busulfan. Busulfan administration depleted blood platelet counts by $40 \%$ (busulfan-treated wild-type mice: $3.8 \pm$ $1.0 \times 10^{5} / \mu \mathrm{l}$ versus untreated wild-type mice: $6.4 \pm 1.3 \times$ $10^{5} / \mu 1, P<0.01$; Table 1). Injection of control vehicle did not alter platelet counts (data not shown). No significant differences in the total number of circulating leukocytes and neutrophils were observed in 5 to 10 experimental groups of mice. Busulfan treatment only marginally affected total circulating leukocytes (busulfan-treated wildtype mice: $8.2 \pm 2.3 \times 10^{3} / \mu$ l versus untreated wild-type mice: $9.3 \pm 2.5 \times 10^{3} / \mu \mathrm{l} ; 12 \%$ depletion), but it did not significantly reduce blood neutrophil numbers (busulfantreated wild-type mice: $1.8 \pm 0.6 \times 10^{3} / \mu$ l versus untreated wild-type mice: $2.0 \pm 0.7 \times 10^{3} / \mu l ; 10 \%$ depletion).

\section{Effect of Platelet Depletion by Busulfan on the Cutaneous Arthus Reaction}

Cutaneous inflammation induced by the Arthus reaction can be separated into two distinct responses: edema, which reaches a maximum at 3 to 4 hours after IC challenge, and hemorrhage, which peaks in intensity at 8 hours. ${ }^{7}$ To assess the role of platelets in the cutaneous Arthus reaction, edema and hemorrhage were evaluated 4 and 8 hours after IC challenge, respectively, in P-selectin $^{-1-}$, E-selectin ${ }^{-1-}$, PSGL-1 ${ }^{-1-}$, and wild-type mice with or without treatment with busulfan. Edema and hemorrhage were not detected in mutant and wild-type mice following intradermal injection of rabbit polyclonal IgG with systemic chicken egg albumin (Figure 1 and data not shown). When edema was assessed by measuring the diameter of Evans blue dye in the extravascular space, edema was significantly reduced in P-selectin ${ }^{-1-}$ (35\% decrease, $P<0.001)$, PSGL-1 $1^{-1-}(58 \%, P<$ 0.0001 ) and, to a lesser degree, busulfan-treated wildtype $(25 \%, P<0.001)$ mice compared with untreated wild-type mice (Figure 1A). However, E-selectin ${ }^{-1-}$ mice developed edema that was similar to that found in wildtype mice. Busulfan administration in E-selectin ${ }^{-1-}$ mice before the induction of the Arthus reaction inhibited edema by $24 \%$ relative to untreated $\mathrm{E}$-selectin ${ }^{-1}$ mice $(P<0.05)$. By contrast, the inhibitory effect by busulfan was not observed in P-selectin ${ }^{-1-}$ or PSGL-1 ${ }^{-1-}$ mice. Busulfan treatment in wild-type mice inhibited edema to a similar level of untreated P-selectin ${ }^{-1-}$ mice, but the inhibitory effect was smaller than the inhibition associated with PSGL-1 ${ }^{-1-}$ mice $(P<0.001)$.

Hemorrhage was macroscopically quantitated after 8 hours by measuring the size of the purpuric spot. Hemorrhage was significantly inhibited in P-selectin ${ }^{-1-}(51 \%$ decrease, $P<0.01)$, PSGL-1 ${ }^{-1-}(54 \%, P<0.01)$, and busulfan-treated wild-type $(28 \%, P<0.05)$ mice compared with untreated wild-type mice (Figure 1B). E-selectin $^{-1-}$ mice treated with busulfan exhibited significantly reduced hemorrhage compared with untreated E-selectin $^{-1-}$ mice $(P<0.05)$. By contrast, busulfan treatment did not affect hemorrhage in P-selectin ${ }^{-1-}$ and PSGL$1^{-1-}$ mice. In addition, the difference between busulfantreated wild-type and untreated PSGL-1 ${ }^{-1-}$ mice was no longer observed for hemorrhage. Thus, platelet depletion by busulfan administration resulted in a greater inhibition 
A

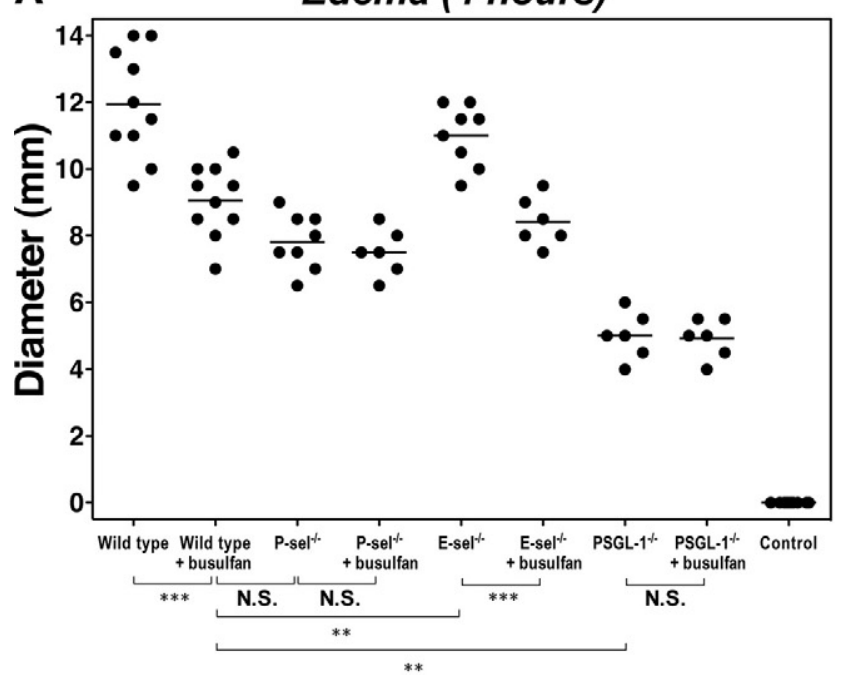

B

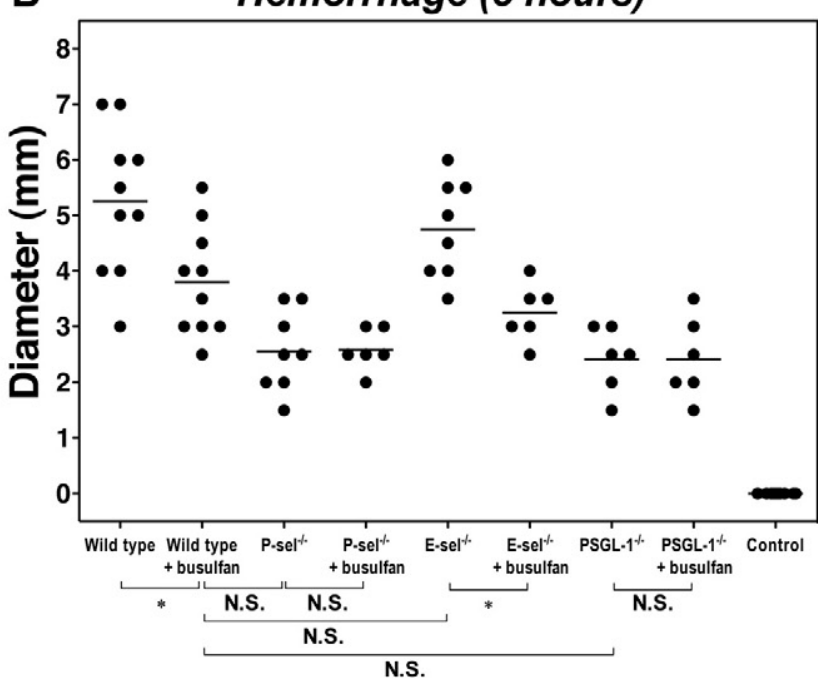

Figure 1. The effect of platelet depletion on edema and hemorrhage in the cutaneous reverse passive Arthus reaction. Mice were injected intradermally with rabbit IgG anti-chicken egg albumin Ab, then intravenously with chicken egg albumin and 1\% Evans blue dye. After 4 or 8 hours, dorsal skins were assessed from wild-type, P-selectin (P-sel) ${ }^{-/}$, E-selectin (E-sel) ${ }^{-/-}$, and PSGL-1 ${ }^{-/-}$mice with or without busulfan treatment. Edema was evaluated after 4 hours as the diameter of extravasated Evans blue spot (A). Hemorrhage after 8 hours was assessed as the diameter of the purpuric spot (B). Wild-type mice that received an intradermal injection of polyclonal rabbit IgG followed by intravenous installation of chicken egg albumin served as controls (control). Horizontal bars indicate mean values of each group. N.S. $=$ not significant. ${ }^{*} P<0.05,{ }^{* * *} P<0.01,{ }^{*}{ }^{* * *} P<0.001$

of edema and hemorrhage in wild-type and E-selectin ${ }^{-/-}$ mice, but not in P-selectin ${ }^{-1-}$ and PSGL-1 ${ }^{-1-}$ mice.

\section{Leukocyte and Mast Cell Infiltration in the Cutaneous Arthus Reaction}

Numbers of neutrophils that migrated outside the blood vessels were assessed in the skin tissues by H\&E staining (Figures 2 and 3). Before IC challenge, there were no significant differences in cutaneous neutrophil numbers between mutant and wild-type mice. After 4 hours of IC formation, neutrophil numbers were significantly reduced in $\mathrm{P}$-selectin ${ }^{-1-}$ (38\% decrease, $\left.P<0.001\right)$, PSGL-1 ${ }^{-1-}$ (50\%, $P<0.001)$, and busulfan-treated wild-type (29\%, $P<0.001)$ mice compared with untreated wild-type mice (Figures $2 \mathrm{~A}$ and $3 \mathrm{~A}$ ). Neutrophil numbers were similar between E-selectin ${ }^{-1-}$ and wild-type mice. There were no significant differences between busulfan-treated wild- type, untreated P-selectin ${ }^{-1-}$, and untreated PSGL-1 ${ }^{-1-}$ mice. Similar results were obtained after 8 hours of IC formation except for significant difference between busulfan-treated wild-type or untreated P-selectin ${ }^{-1-}$ mice and untreated PSGL-1 ${ }^{-1-}$ mice $(P<0.001$; Figures $2 \mathrm{~A}$ and $3 \mathrm{~B}$ ).

Four hours after IC challenge, mast cell numbers were significantly reduced in $\mathrm{P}$-selectin ${ }^{-1-}(34 \%$ decrease, $P<0.001)$, PSGL-1 ${ }^{-1-}(41 \%, P<0.001)$, and busulfantreated wild-type $(30 \%, P<0.001)$ mice relative to untreated wild-type mice (Figures $2 \mathrm{~B}$ and $3 \mathrm{C}$ ). Mast cell numbers did not significantly differ between E-selec$\mathrm{tin}^{-1-}$ and wild-type mice. There were no significant differences between busulfan-treated wild-type, untreated P-selectin ${ }^{-1-}$, and untreated PSGL-1 ${ }^{-1-}$ mice. However, 8 hours after IC challenge, no significant difference in mast cell numbers was observed among any groups (Figures 2B and 3D). No neutrophil and mast cell influx
A

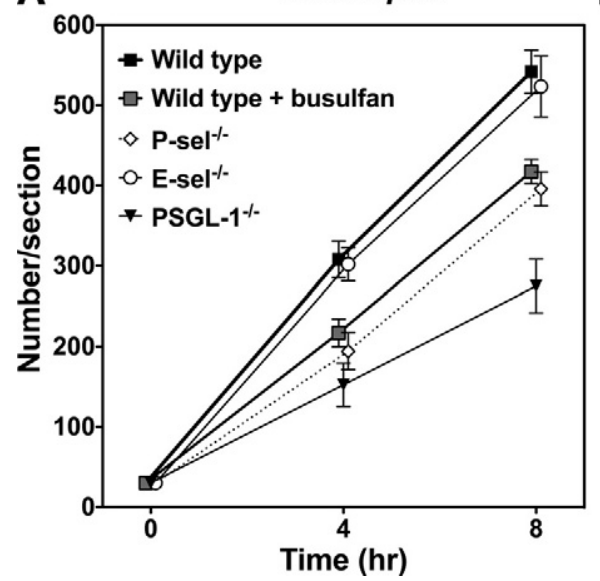

B

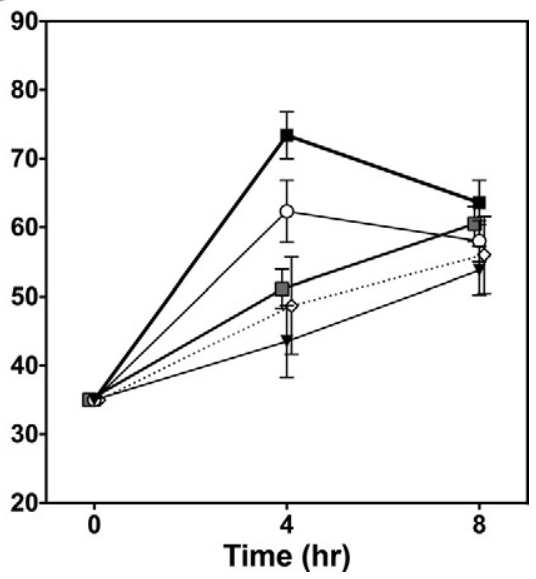

Figure 2. Arthus reaction-induced recruitment of neutrophils and mast cells in the skin from wild-type mice, wild-type mice treated with busulfan, E-selectin (E-sel) ${ }^{-/-}$mice, P-selectin $(\mathrm{P}-\mathrm{sel})^{-1-}$ mice, and PSGL-1 ${ }^{-/-}$mice at 4 and 8 hours after IC challenge. Numbers of neutrophils and mast cells per skin section were examined in H\&E- and toluidine blue-stained skin sections, respectively. All values represent the means \pm SEM calculated on the results obtained from 5 to 10 mice in each group. Statistical analysis is provided in the Results section. 


\section{A 4 hours B 8 hours C 4 hours D 8 hours}

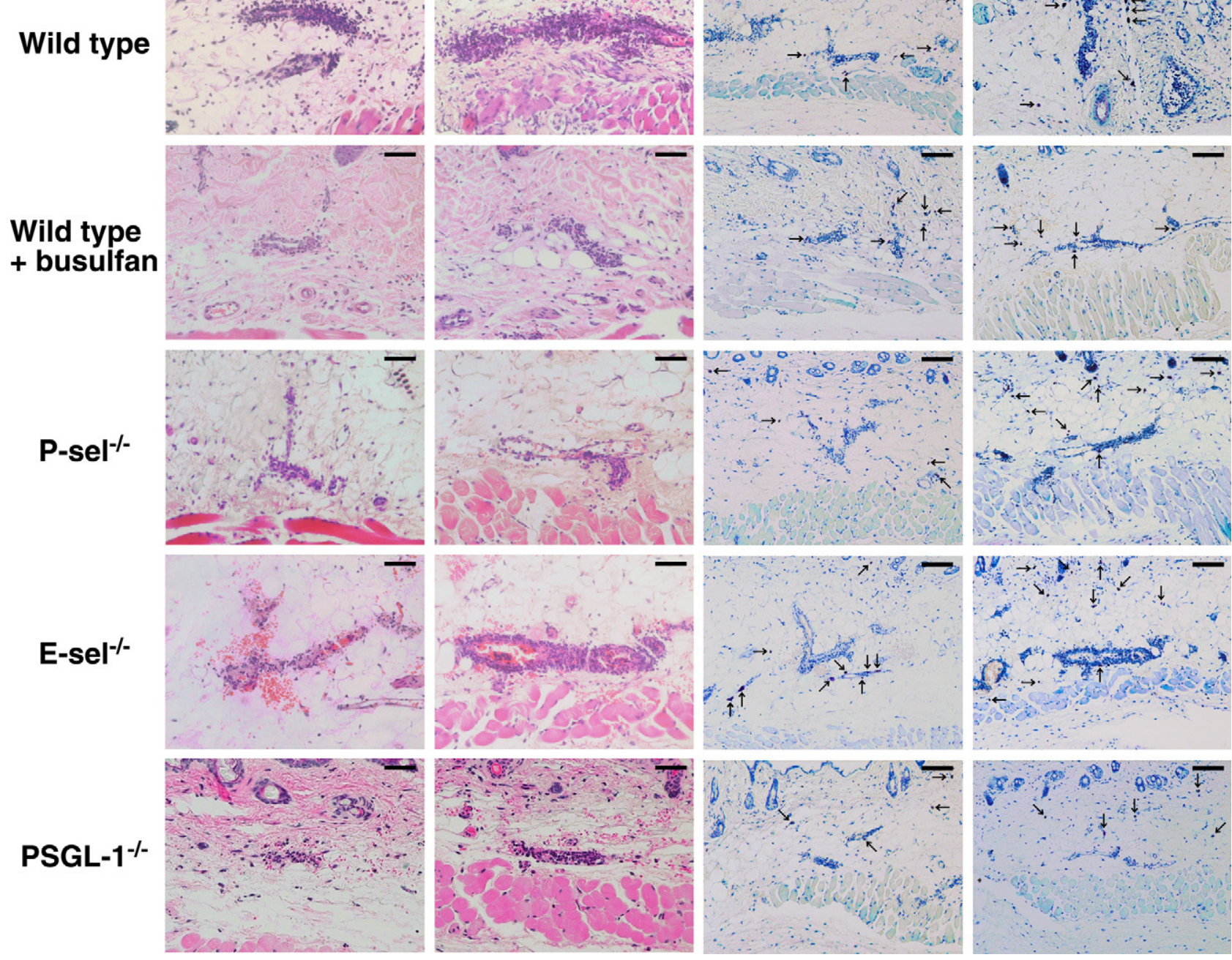

Figure 3. Representative inflammatory cell recruitment in the skin from wild-type mice, wild-type mice treated with busulfan (wild-type + busulfan), P-selectin (P-sel) $^{-1-}$ mice, E-selectin (E-sel) ${ }^{-1}$ mice, and PSGL-1 ${ }^{-1-}$ mice. A, B: Neutrophils were detected by H\&E staining at 4 and 8 hours after IC challenge. Original magnification, $\times 100$. Scale bars $=50 \mu \mathrm{m}$. C, D: Mast cells (arrows) were detected as cells with metachromatic staining of granules in toluidine blue-stained sections at 4 and 8 hours after IC challenge. Original magnifications, $\times 50$. Scale bars $=100 \mu \mathrm{m}$.

was detected in mice following intradermal injection of rabbit polyclonal IgG with systemic chicken egg albumin (data not shown). In addition, no significant differences in the total number of circulating leukocytes and neutrophils were observed in 5 to 10 experimental groups of mice, so that the changes in edema, hemorrhage, and leukocyte infiltration could not be attributed to leukopenia (Table 1).

Further we assessed the association of blood platelet numbers with edema, hemorrhage, or cutaneous leukocyte numbers in thrombocytopenic mice. Regarding edema and hemorrhage formation during the cutaneous Arthus reaction, blood platelet numbers were correlated positively with these parameters $(P<0.05, r=0.525$, and $P<0.05, r=0.509$, respectively; Figures 4$)$. In addition, cutaneous neutrophil numbers at 4 hours were also correlated positively with blood platelet numbers $(P<0.05, r=0.443)$. Moreover, the inhibitory effect on neutrophil recruitment at 8 hours tended to correlate with decreased levels of blood platelet counts $(P=0.07, r=$ 0.410). However, no significant correlation was found between blood platelet numbers and mast cell accumulation in the skin during the cutaneous Arthus reaction. Collectively, platelet depletion by busulfan treatment had inhibitory effects on leukocyte recruitment in the cutaneous Arthus reaction.

\section{Pro-Inflammatory Cytokine and Platelet-Derived Chemokine mRNA Expression in the Cutaneous Arthus Reaction}

Expression of IL-6, TNF- $\alpha$, PF4, MCP-1, and RANTES in the skin tissue was quantitated after 4 and 8 hours of IC formation by real-time PCR (Figure 5). There was no significant difference in any cytokine expression between E-selectin $^{-1-}$ and wild-type mice. By contrast, mRNA 

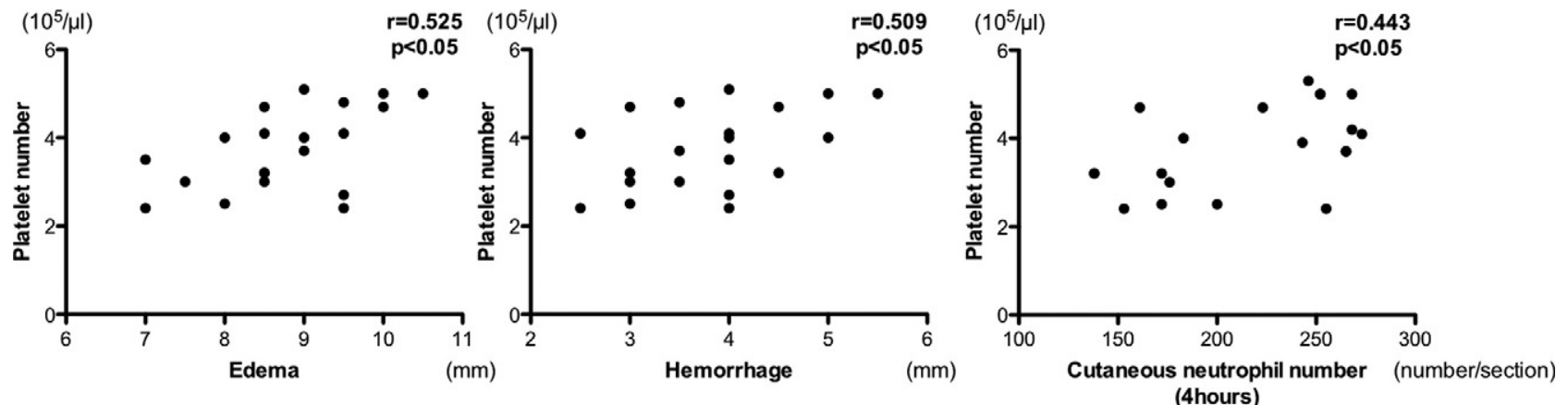

Figure 4. Correlation of circulating platelet counts against edema, hemorrhage, and neutrophil recruitment in the skin during the cutaneous reverse passive Arthus reaction. Edema, hemorrhage, and neutrophil recruitment were induced and evaluated in wild-type mice treated with busulfan, as described in Figure 1.

levels of all cytokines examined in this study were significantly reduced in busulfan-treated wild-type, untreated P-selectin ${ }^{-1-}$, and untreated PSGL-1 ${ }^{-1-}$ mice relative to untreated wild-type mice at 4 hours after the IC challenge. However, such difference was not observed at 8 hours after IC challenge. There were no significant differences in any cytokine expression between busulfantreated wild-type, untreated P-selectin ${ }^{-1-}$, and untreated PSGL-1 ${ }^{-1-}$ mice. Thus, the reduced cutaneous inflammatory responses by platelet depletion were generally

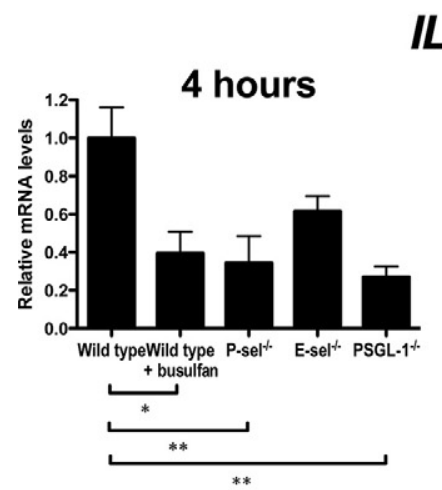

IL-6

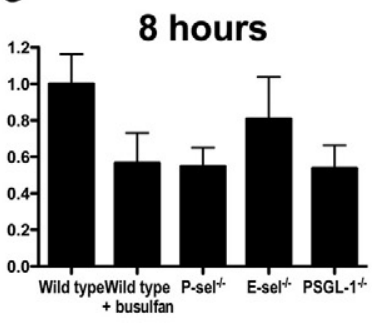

PF4/CXCL4
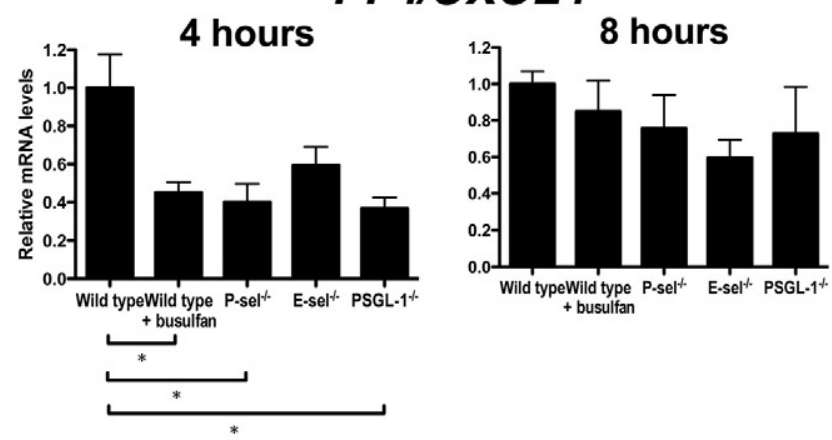

RANTES/CCL5
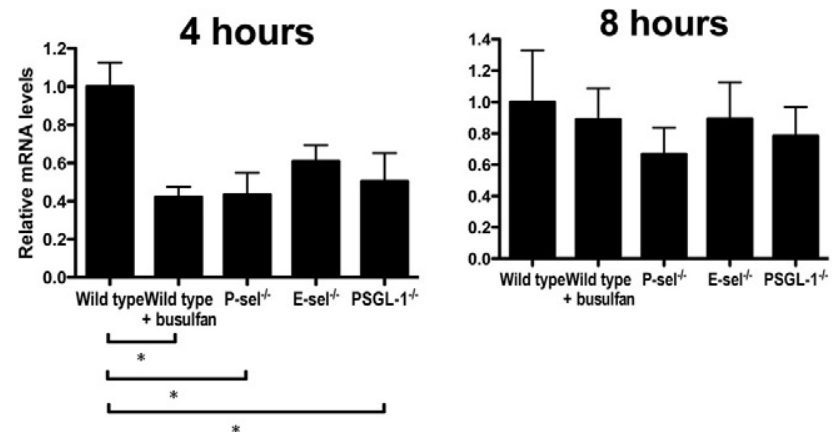

\section{$T N F-\alpha$}
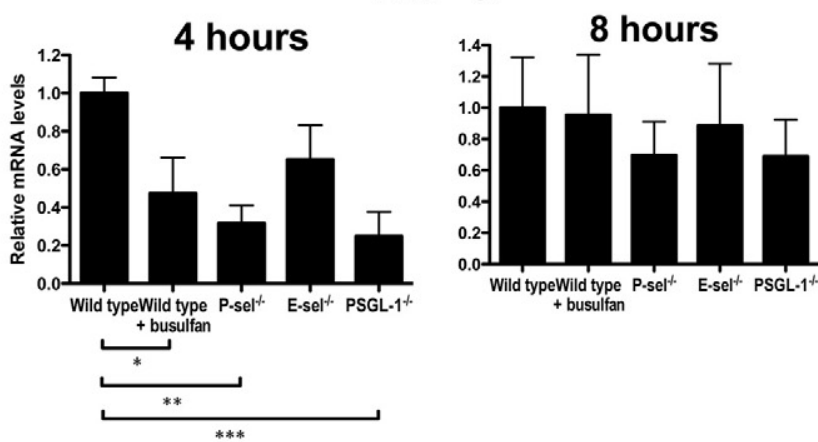

$M C P-1 / C C L 2$
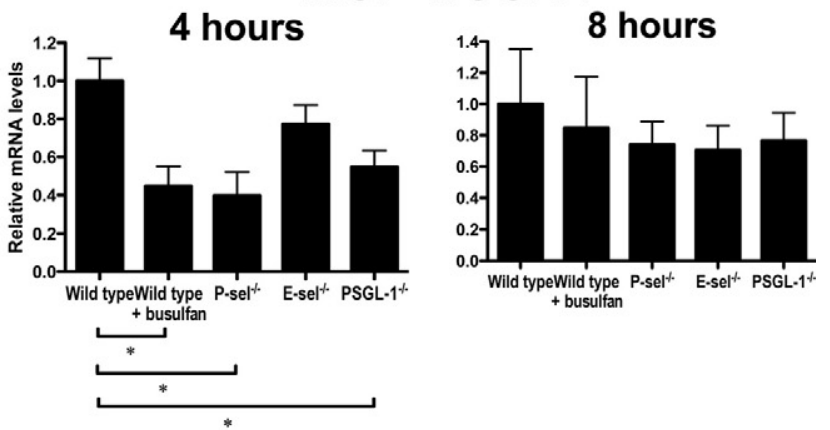

Figure 5. Arthus reaction-induced expression of IL- 6 , TNF- $\alpha$, PF $4 / C X C L 4$ MCP-1/CCL2, and RANTES/CCL5 in the skin from untreated wild-type mice, wild-type mice treated with busulfan (wild-type + busulfan), P-selectin (P-sel) $^{-/-}$mice, E-selectin (E-sel) ${ }^{-/-}$mice, and PSGL- ${ }^{-/-}$mice at 4 and 8 hours after IC challenge. Total RNA was isolated from frozen skin tissues, reverse transcribed into cDNA, and then amplified using primers. Relative mRNA levels of IL-6, TNF- $\alpha$, PF4, MCP-1, and RANTES in the skin samples were measured by real-time PCR and normalized relative to that of GADPH as an endogenous control. All values represent the mean \pm SEM of results obtained from 5 to 8 mice in each group. ${ }^{*} P<0.05$, ${ }^{* * *} P<0.01,{ }^{*}{ }^{* * *} P<0.001$ 


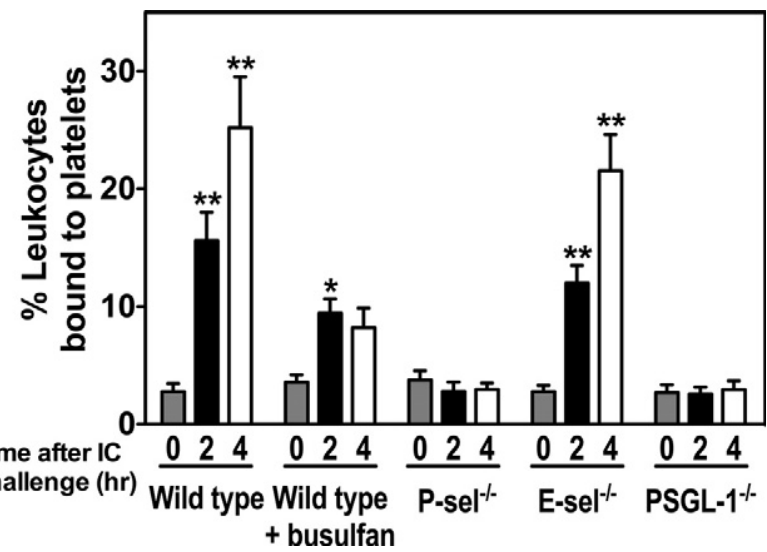

Figure 6. Arthus reaction-induced platelet-leukocyte aggregate formation in whole blood from wild-type mice, wild-type mice treated with busulfan (wild-type + busulfan), E-selectin $(\mathrm{E}-\mathrm{sel})^{-/-}$mice, P-selectin $(\mathrm{P}-\mathrm{sel})^{-1-}$ mice, and PSGL-1 $1^{-1-}$ mice before and at 2 and 4 hours after IC challenge. The percentages of leukocytes bound to platelets were assessed by flow cytometry. Platelets were identified with an anti-CD 41 antibody. Leukocytesized events were selected on the forward and side scattering profiles and the accuracy of the gating confirmed by staining with CD 45. Events staining positive for both CD 45 and CD41 were considered to represent plateletleukocyte aggregates and were distinguishable from events staining for CD 45 alone. All values represent the mean \pm SEM of results obtained from five mice in each group. ${ }^{*} P<0.05$ and ${ }^{* *} P<0.001$, versus levels before IC challenge in each group of mice.

associated with the reduced release of IL-6, TNF- $\alpha, \mathrm{PF} 4$, MCP-1, and RANTES.

\section{Detection of Platelet-Leukocyte Aggregates by Flow Cytometry}

Reduced Arthus reaction-induced leukocyte accumulation in busulfan-treated mice indicates a role of platelets in leukocyte recruitment. To further investigate whether circulating platelets can interact with leukocytes during the cutaneous Arthus reaction, platelet-leukocyte aggregates in circulating blood of mice were examined by flow cytometry. The accuracy of the identification of leukocytes by forward and side scatter was confirmed by staining with an antibody to CD45. More than $98 \%$ of cells gated on these characteristics of size and granularity were CD45 positive. Percentages of leukocytes positive for the platelet-specific marker CD41 were measured in five experimental groups of mice before and after 2 and 4 hours of IC formation. These represent the frequency of platelet-leukocyte aggregates. The frequency of plateletleukocyte aggregates was significantly increased by 5.6fold after 2 hours and 9.1-fold after 4 hours of IC formation compared with the levels before IC challenge in wild-type mice $(P<0.001$ and $P<0.001$, respectively; Figure 6). A similar increase in the frequency of platelet-leukocyte aggregates was observed in E-selectin ${ }^{-1-}$ mice. In thrombocytopenic mice, the frequency of platelet-leukocyte aggregates was elevated at 2 hours $(P<0.05)$, but was 39\% lower than those found in wild-type mice at the same time point $(P=0.09)$. Four hours after IC challenge, further increased tendency for platelet-leukocyte aggregate formation in thrombocytopenic mice was not observed: the frequency of platelet-leukocyte aggregates was reduced by $67 \%$ compared with those found in wild-type mice $(P<0.01)$. Additionally, $P$-selectin ${ }^{-1-}$ and PSGL-1 $1^{-/-}$mice showed no significant increase in the frequency of platelet-leukocyte aggregates after IC challenge. These results indicate that the cutaneous Arthus reaction induces formation of platelet-leukocyte aggregates that decreased by busulfan administration. Moreover, P-selectin and PSGL-1 expression was shown to be important for induction of platelet-leukocyte aggregate formation during the cutaneous Arthus reaction.

\section{Effect of Platelet Restoration on Cutaneous Arthus Reaction}

The increase in P-selectin and PSGL-1-dependent platelet-leukocyte aggregates after IC challenge suggests that P-selectin on platelets may play an important role in leukocyte recruitment during cutaneous Arthus reaction. To investigate the role of platelet P-selectin on leukocyte recruitment in cutaneous Arthus reaction, the effects of platelet restoration were examined in busulfan-treated wild-type mice. Washed platelets obtained from P-selec$\mathrm{tin}^{-1-}$ or wild-type mice were injected intravenously into busulfan-treated wild-type mice 20 minutes before IC challenge. The edema and hemorrhage formation after IC challenge significantly increased after platelet restoration compared with that under thrombocytopenic condition $(P<0.001$ and $P<0.05$, respectively; Figures 7A and 7B). In contrast, when busulfan-treated wild-type mice restored with platelets obtained from $\mathrm{P}$-selectin ${ }^{-1-}$ mice, these parameters were similar to those seen in thrombocytopenic mice. In addition, injection of platelets obtained from wild-type mice led to increased neutrophil infiltration after 4 and 8 hours $(P<0.01$ and $P<0.01$, respectively; Figure $7 C$ ) and mast cell accumulation after 4 hours of $\mathrm{IC}$ formation $(P<0.05$; Figure $7 \mathrm{D})$ in the skin relative to those found in busulfan-treated wild-type mice. However, platelets obtained from P-selectin ${ }^{-1-}$ type mice did not affect cutaneous neutrophil and mast cell numbers after IC challenge. These results indicate that platelet $\mathrm{P}$-selectin is important for leukocyte recruitment in the skin.

\section{Discussion}

In the present study, IC-mediated edema and hemorrhage were significantly inhibited in busulfan-treated wild-type mice compared with untreated wild-type mice. This inhibitory effect of platelet depletion on the cutaneous Arthus reaction was generally associated with reduced infiltration of neutrophils and mast cells and decreased expression of various pro-inflammatory cytokines and platelet-derived chemokines. Furthermore, platelet-leukocyte aggregates were formed in circulating blood of wild-type mice that received IC challenge. In addition, platelet depletion by busulfan administration before the induction of Arthus reaction led to a significant decrease in the percentage of leukocytes attached to platelets. Furthermore, the cutaneous Arthus reaction in thrombocytopenic mice was restored by platelet infusion. Taken 
A
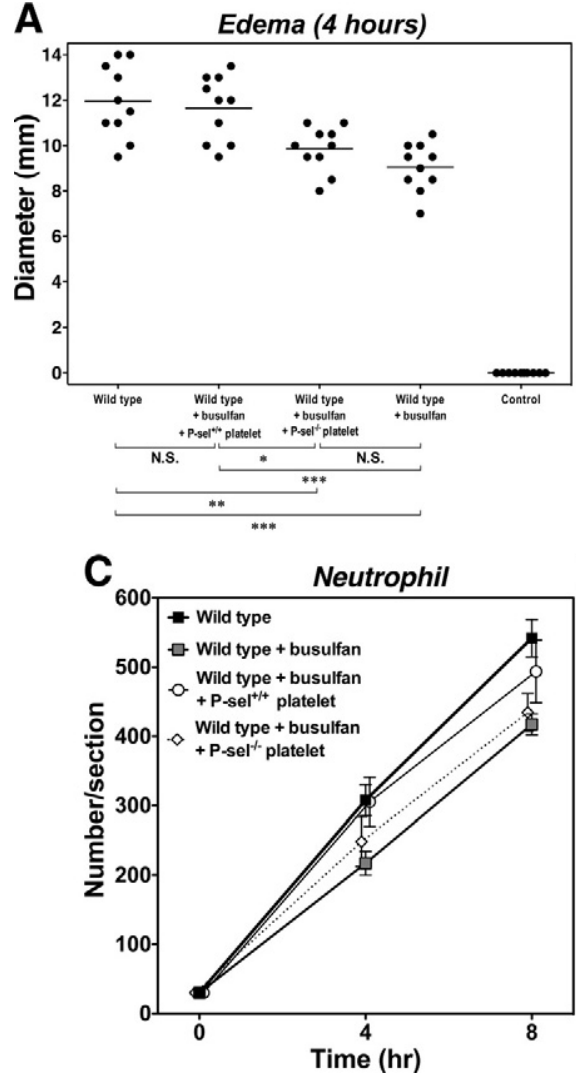

B

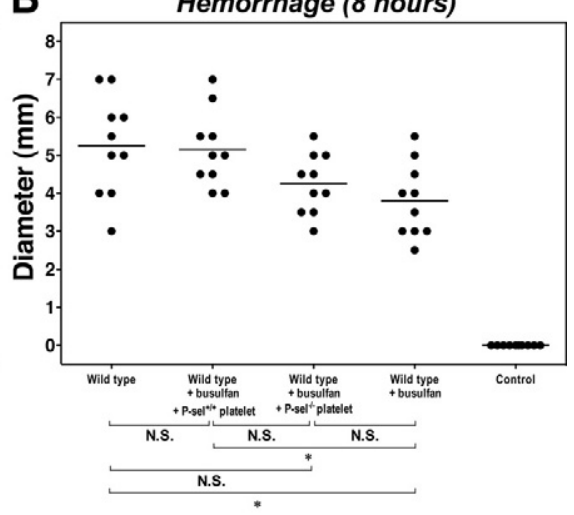

D

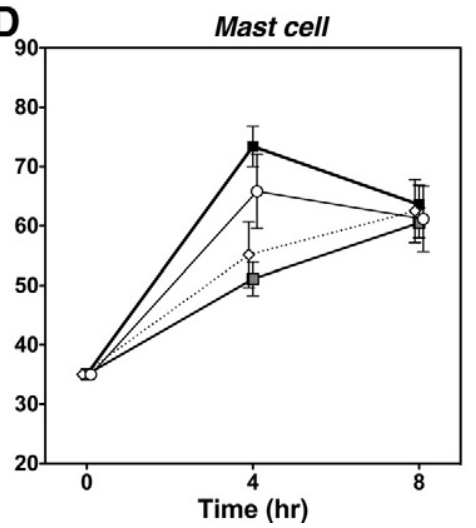

Figure 7. The effect of platelet restoration on edema and hemorrhage formation and leukocyte recruitment in the skin during the cutaneous reverse passive Arthus reaction. Washed platelets were isolated from the blood of wild-type or P-selectin $^{-/-}$mice. The resulting platelet suspension was injected intravenously into busulfan-treated wild-type mice 20 minutes before the IC challenge Edema (A) and hemorrhage (B) were induced and evaluated in wild-type mice, busulfan-treated wildtype mice (wild-type + busulfan), busulfan-treated wild-type mice restored with platelets obtained from wild-type mice (wild-type + busulfan + ${\mathrm{P}-\mathrm{sel}^{+/+}}^{+/ a t e l e t),}$ or busulfan-treated wild-type mice restored with platelets obtained from P-selec$\mathrm{tin}^{-1-}$ mice (wild-type + busulfan $+\mathrm{P}_{-} \mathrm{sel}^{-1}$ platelet), as described in Figure 1. Numbers of neutrophils (C) and mast cells (D) were also examined in H\&E- and toluidine blue-stained skin sections, respectively. Horizontal bars indicate mean values of each group $(\mathbf{A}, \mathbf{B})$. All values represent the means \pm SEM calculated on the results obtained from 5 to 10 mice in each group (C, D). N.S. $=$ not significant. ${ }^{*} P<0.05,{ }^{* *} P<0.01$ ${ }_{* * * * *} P<0.001$. together, the results of this study demonstrate an essential role of platelets for the leukocyte recruitment to the skin in a murine model of cutaneous Arthus reaction.

Busulfan administration in E-selectin ${ }^{-1-}$ mice inhibited the cutaneous Arthus reaction to a similar extent of the inhibition observed in busulfan-treated wild-type mice. In contrast, busulfan treatment did not affect the cutaneous Arthus reaction in $\mathrm{P}$-selectin ${ }^{-/-}$or PSGL-1 ${ }^{-1-}$ mice, suggesting that $\mathrm{P}$-selectin and PSGL-1 are important for the platelet-mediated recruitment process. In vitro studies have shown that PSGL-1 binds P-selectin, but also binds E- and L-selectins with lower affinity. ${ }^{41-44}$ At 4 hours after IC challenge, edema formation in busulfan-treated wildtype mice was inhibited to a similar level of untreated P-selectin ${ }^{-1-}$ mice, suggesting that P-selectin plays a major role in the platelet-mediated recruitment process. By contrast, inhibition of edema in untreated PSGL-1 ${ }^{-1-}$ mice was greater than that found in busulfan-treated wild-type mice. However, such difference was not observed at 8 hours after IC challenge. Therefore, these results suggest that in early phase of the cutaneous Arthus reaction, PSGL-1 interacts with E-selectin in addition to P-selectin. Nonetheless, P-selectin and PSGL-1 interaction appeared to play a predominant role in the platelet-mediated recruitment process during the cutaneous Arthus reaction.

P-selectin is an integral membrane glycoprotein expressed by platelets and activated endothelial cells. Pselectin expression on platelets, but not on endothelial cells, has been shown to be responsible for leukocyte rolling along endothelium. ${ }^{45,46}$ P-selectin on platelets is an important adhesion molecule for PSGL-1-bearing immune cells, as it mediates adhesion of activated platelets to monocytes, neutrophils, and lymphocytes, resulting in the formation of platelet-leukocyte complexes that support leukocyte rolling and arrest on surface-adherent platelets. ${ }^{45-47}$ Consistently, our results from flow cytometric analysis indicate the interactions between platelets and leukocytes during the cutaneous Arthus reaction. Furthermore, our platelet restoration studies showed that $\mathrm{P}$-selectin on platelets is necessary for platelet-mediated recruitment process during cutaneous Arthus reaction. Platelet attachment to leukocytes, by binding of P-selectin on platelets to its ligand PSGL-1 on leukocytes, increases the expression of adhesion molecules on the surface of leukocytes, priming them for diapedesis through vessel walls. ${ }^{48}$ Additionally, recent studies have shown that purified P-selectin stimulates platelet-leukocyte aggregation and adhesion of leukocytes to intercellular adhesion molecule- 1 on endothelium. ${ }^{49,50}$ Collectively, these observations suggest that P-selectin on platelets is crucial for the recruitment of immune cells by dual action as an adhesion and signaling molecules.

Activated platelets secrete a number of potent inflammatory and mitogenic substances into the local microenvironment. ${ }^{14}$ These mediators modulate functions of other platelets, leukocytes, and endothelial cells. Proinflammatory cytokines, including TNF- $\alpha$ and IL-6, are produced and released by mast cells, neutrophils, and monocytes. ${ }^{51,52}$ PF4, MCP-1, and RANTES, released on platelet activation, are chemotactic and can activate leukocytes. In this study, mRNA expression of IL-6, TNF- $\alpha$, 
PF4, MCP-1, and RANTES was significantly elevated in wild-type mice that received IC challenge, whereas levels of these cytokines significantly decreased in busulfantreated wild-type, P-selectin ${ }^{-1-}$, and PSGL-1 ${ }^{-1-}$ mice at the early phase. A previous study has shown that activation of either leukocytes or platelets alone has the same effects as simultaneous activation of both cell types, suggesting that leukocytes and platelets activate each other. ${ }^{27}$ Moreover, platelet-derived chemokines attract and stimulate leukocytes and further activate other platelets. In the presence of appropriate co-stimuli such as TNF- $\alpha$, PF4 can activate neutrophils and induce exocytosis and firm neutrophil adhesion to endothelial cells. ${ }^{53}$ PF4 can also influence platelet function by inducing platelet aggregation, stimulating platelet adhesion to collagen and fibrinogen, and increasing P-selectin expression. ${ }^{54}$ MCP-1 and RANTES do not have dramatic effects on neutrophils, but enhance paracrine activation of other platelets. ${ }^{14}$ In addition to interacting with neutrophils, platelets interact with other leukocyte subpopulations. ${ }^{14}$ MCP-1 released by platelets plays a key role in the regulation of monocyte recruitment to inflamed tissue. Interleukin-1 $\beta$, also released from activated platelets, promote neutrophil and monocyte adhesion to the endothelium. ${ }^{20}$ RANTES is mainly a monocyte chemoattractant, but it can also attract various $T$ cell subtypes. P-selectin on activated platelets has been shown to be necessary for the presentation of inflammatory mediators to monocytes, allowing RANTES-dependent monocyte recruitment in the process that requires the formation of circulating platelet-monocyte aggregates. ${ }^{55,56}$ In addition, a previous study have shown that injection of supernatant of activated platelets, which contained various chemokines including RANTES, into the skin induces leukocyte infiltration. ${ }^{33}$ Thus, platelets not only bind to different subsets of leukocytes, enhancing their contact with endothelium, but also can secrete mediators, triggering leukocyte arrest and inducing transendothelial migration.

In the current study, cytokine production in thrombocytopenic mice was significantly reduced at 4 hours after IC challenge. In flow cytometric analysis, formation of platelet-leukocyte aggregates in untreated wild-type mice was gradually increased till 4 hours, whereas that in busulfan-treated wild-type mice peaked at 2 hours after IC challenge: as a result, the frequency of platelet-leukocyte aggregates was reduced by $67 \%$, as compared with that in untreated wild-type mice. Therefore, there were significant differences in the frequency of platelet-leukocyte aggregates between untreated and busulfan-treated wild-type mice. Previous study has shown that activation of either leukocyte or platelet alone has the same effects as simultaneous activation of both cell types, suggesting that leukocytes and platelets activate each other and thereby influence the release of cytokines from these cells. ${ }^{27}$ Thus, decreased formation of platelet-leukocyte aggregates and impairment of mutual cell activation may contribute to markedly reduced release of cytokines after 4 hours of IC formation in thrombocytopenic mice. Interactions between neutrophils and platelets promote mutual cell activation and platelet-endothelial interactions facilitate the secondary capture of neutrophils and other leukocytes. ${ }^{57}$ Following the initiation of neutrophil-platelet interaction, the reciprocal activation of both cells via outside-in signaling mechanisms could account for the subsequent firm adhesion of neutrophils. In addition, plateletleukocyte aggregate formation has been shown to increase the expression of endothelial adhesion molecules such as intercellular adhesion molecule-1 and cytokine release from endothelial cells. ${ }^{20,27}$ Thus, leukocytes within platelet-leukocyte complexes have increased capacity to the activated endothelium. Collectively, these findings suggest that the development of the cutaneous Arthus reaction is dependent in part on the presence of platelets by interacting with leukocytes.

\section{Acknowledgments}

We thank Ms. Yuko Yamada, Masako Matsubara, Aya Usui, Mariko Yozaki, and Kaori Shimoda for technical assistance.

\section{References}

1. Kohl J, Gessner JE: On the role of complement and FC gammareceptors in the Arthus reaction. Mol Immunol 1999, 36:893-903

2. Arthus M: Injections répetées de serum de cheval chez le lapin. VR SocBiol 1903, 55:817-820

3. Baumann U, Chouchakova N, Gewecke B, Kohl J, Carroll MC, Schmidt RE, Gessner JE: Distinct tissue site-specific requirements of mast cells and complement components C3/C5a receptor in IgG immune complex-induced injury of skin and lung. J Immunol 2001, 167:1022-1027

4. Baumann U, Kohl J, Tschernig T, Schwerter-Strumpf K, Verbeek JS, Schmidt RE, Gessner JE: A codominant role of FC gamma RI/III and C5aR in the reverse Arthus reaction. J Immunol 2000, 164:1065-1070

5. Hopken UE, Lu B, Gerard NP, Gerard C: Impaired inflammatory responses in the reverse arthus reaction through genetic deletion of the C5a receptor. J Exp Med 1997, 186:749-756

6. Kaburagi Y, Hasegawa M, Nagaoka T, Shimada Y, Hamaguchi Y, Komura K, Saito E, Yanaba K, Takehara K, Kadono T, Steeber DA, Tedder TF, Sato S: The cutaneous reverse Arthus reaction requires intercellular adhesion molecule 1 and L-selectin expression. J Immunol 2002, 168:2970-2978

7. Sylvestre DL, Ravetch JV: FC receptors initiate the Arthus reaction: redefining the inflammatory cascade. Science 1994, 265:1095-1098

8. Zhang Y, Ramos BF, Jakschik BA: Augmentation of reverse arthus reaction by mast cells in mice. J Clin Invest 1991, 88:841-846

9. Springer TA: Signals on endothelium for lymphocyte recirculation and leukocyte emigration: the area code paradigm. Harvey Lect 1993, 89:53-103

10. Butcher EC: Leukocyte-endothelial cell recognition: three (or more) steps to specificity and diversity. Cell 1991, 67:1033-1036

11. Tedder TF, Li X, Steeber DA: The selectins and their ligands: adhesion molecules of the vasculature. Adv Mol Cell Biol 1999, 28:65-111

12. McEver R: Adhesive interactions of leukocytes, platelets, and the vessel wall during hemostasis and inflammation. Thromb Haemost 2001, 86:746-756

13. von Hundelshausen $P$, Weber $C$ : Platelets as immune cells: bridging inflammation and cardiovascular disease. Circ Res 2007, 100:27-40

14. Zarbock A, Polanowska-Grabowska R, Ley K: Platelet-neutrophilinteractions: linking hemostasis and inflammation. Blood Rev 2007, 21:99-111

15. Frenette P, Moyna C, Hartwell D, Lowe J, Hynes R, Wagner D: Platelet-endothelial interactions in inflamed mesenteric venules. Blood 1998, 91:1318-1324

16. Frenette PS, Johnson RC, Hynes RO, Wagner DD: Platelets roll on stimulated endothelium in vivo: an interaction mediated by endothelial P-selectin. Proc Natl Acad Sci USA 1995, 92:7450-7454 
17. Holmsen $\mathrm{H}$ : Significance of testing platelet functions in vitro. Eur J Clin Invest 1994, 24 Suppl 1:3-8

18. Schmitt-Sody M, Klose A, Gottschalk O, Metz P, Gebhard H, Zysk S, Eichhorn M, Hernandez-Richter T, Jansson V, Veihelmann A: Plateletendothelial cell interactions in murine antigen-induced arthritis. Rheumatology (Oxford) 2005, 44:885-889

19. Jeffery PK, Wardlaw AJ, Nelson FC, Collins JV, Kay AB: Bronchial biopsies in asthma. An ultrastructural, quantitative study and correlation with hyperreactivity. Am Rev Respir Dis 1989, 140:1745-1753

20. Gawaz M, Langer H, May A: Platelets in inflammation and atherogenesis. J Clin Invest 2005, 115:3378-3384

21. Ludwig R, Schultz J, Boehncke W, Podda M, Tandi C, Krombach F, Baatz H, Kaufmann R, von Andrian U, Zollner T: Activated, not resting, platelets increase leukocyte rolling in murine skin utilizing a distinct set of adhesion molecules. J Invest Dermatol 2004, 122:830-836

22. Pitchford S, Yano H, Lever R, Riffo-Vasquez $Y$, Ciferri S, Rose M Giannini S, Momi S, Spina D, O'connor B, Gresele P, Page C: Platelets are essential for leukocyte recruitment in allergic inflammation. J Allergy Clin Immunol 2003, 112:109-118

23. Yeo EL, Sheppard JA, Feuerstein IA: Role of P-selectin and leukocyte activation in polymorphonuclear cell adhesion to surface adherent activated platelets under physiologic shear conditions (an injury vessel wall model). Blood 1994, 83:2498-2507

24. McEver RP, Martin MN: A monoclonal antibody to a membrane glycoprotein binds only to activated platelets. J Biol Chem 1984 259:9799-9804

25. Hsu-Lin S, Berman CL, Furie BC, August D, Furie B: A platelet membrane protein expressed during platelet activation and secretion. Studies using a monoclonal antibody specific for thrombinactivated platelets. J Biol Chem 1984, 259:9121-9126

26. Mine S, Fujisaki T, Suematsu M, Tanaka Y: Activated platelets and endothelial cell interaction with neutrophils under flow conditions. Intern Med 2001, 40:1085-1092

27. Zarbock A, Singbartl K, Ley K: Complete reversal of acid-induced acute lung injury by blocking of platelet-neutrophil aggregation. J Clin Invest 2006, 116:3211-3219

28. Yanaba K, Komura K, Horikawa M, Matsushita Y, Takehara K, Sato S: P-selectin glycoprotein ligand-1 is required for the development of cutaneous vasculitis induced by immune complex deposition. J Leukoc Biol 2004, 76:374-382

29. Yanaba K, Kaburagi Y, Takehara K, Steeber DA, Tedder TF, Sato S: Relative contributions of selectins and intercellular adhesion molecule-1 to tissue injury induced by immune complex deposition. Am J Pathol 2003, 162:1463-1473

30. Ley K, Kansas GS: Selectins in T-cell recruitment to non-lymphoid tissues and sites of inflammation. Nat Rev Immunol 2004, 4:325-335

31. Pitchford S, Riffo-Vasquez Y, Sousa A, Momi S, Gresele P, Spina D, Page C: Platelets are necessary for airway wall remodeling in a murine model of chronic allergic inflammation. Blood 2004, 103:639-647

32. Vowinkel T, Wood K, Stokes K, Russell J, Tailor A, Anthoni C, Senninger N, Krieglstein C, Granger D: Mechanisms of platelet and leukocyte recruitment in experimental colitis. Am J Physiol Gastrointest Liver Physiol 2007, 293:G1054-G1060

33. Tamagawa-Mineoka R, Katoh N, Ueda E, Takenaka H, Kita M, Kishimoto $\mathrm{S}$ : The role of platelets in leukocyte recruitment in chronic contact hypersensitivity induced by repeated elicitation. Am J Pathol 2007 170:2019-2029

34. Lister KJ, James WG, Hickey MJ: Immune complexes mediate rapid alterations in microvascular permeability: roles for neutrophils, complement, and platelets. Microcirculation 2007, 14:709-722

35. Frenette PS, Mayadas TN, Rayburn H, Hynes RO, Wagner DD: Susceptibility to infection and altered hematopoiesis in mice deficient in both P-and E-selectins. Cell 1996, 84:563-574

36. Yang J, Hirata T, Croce K, Merrill-Skoloff G, Tchernychev B, Williams E, Flaumenhaft R, Furie BC, Furie B: Targeted gene disruption demonstrates that P-selectin glycoprotein ligand 1 (PSGL-1) is required for P-selectin-mediated but not E-selectin-mediated neutrophil rolling and migration. J Exp Med 1999, 190:1769-1782
37. Kuter D, Rosenberg R: The reciprocal relationship of thrombopoietin (c-Mpl ligand) to changes in the platelet mass during busulfaninduced thrombocytopenia in the rabbit. Blood 1995, 85:2720-2730

38. Brecher G. Cronkite EP: Morphology and enumeration of human blood platelets. J Appl Physiol 1950, 3:365-377

39. Shattil S, Cunningham M, Hoxie J: Detection of activated platelets in whole blood using activation-dependent monoclonal antibodies and flow cytometry. Blood 1987, 70:307-315

40. Mustard JF, Perry DW, Ardlie NG, Packham MA: Preparation of suspensions of washed platelets from humans. $\mathrm{Br} \mathrm{J}$ Haematol 1972, 22:193-204

41. Guyer DA, Moore KL, Lynam EB, Schammel CM, Rogelj S, McEver RP, Sklar LA: P-selectin glycoprotein ligand-1 (PSGL-1) is a ligand for L-selectin in neutrophil aggregation. Blood 1996, 88:2415-2421

42. Asa D, Raycroft L, Ma L, Aeed PA, Kaytes PS, Elhammer AP, Geng JG: The P-selectin glycoprotein ligand functions as a common human leukocyte ligand for P- and E-selectins. J Biol Chem 1995, 270:11662-11670

43. Moore KL, Eaton SF, Lyons DE, Lichenstein HS, Cummings RD, McEver RP: The P-selectin glycoprotein ligand from human neutrophils displays sialylated, fucosylated. O-linked poly-N-acetyllactosamine, J Biol Chem 1994, 269:23318-23327

44. Sako D, Comess KM, Barone KM, Camphausen RT, Cumming DA, Shaw GD: A sulfated peptide segment at the amino terminus of PSGL-1 is critical for P-selectin binding. Cell 1995, 83:323-331

45. Diacovo T, Puri K, Warnock R, Springer T, von Andrian U: Plateletmediated lymphocyte delivery to high endothelial venules. Science 1996, 273:252-255

46. Diacovo T, Roth S, Buccola J, Bainton D, Springer T: Neutrophil rolling, arrest, and transmigration across activated, surface-adherent platelets via sequential action of P-selectin and the beta 2-integrin CD11b/CD18. Blood 1996, 88:146-157

47. Larsen E, Celi A, Gilbert G, Furie B, Erban J, Bonfanti R, Wagner D, Furie B: PADGEM protein: a receptor that mediates the interaction of activated platelets with neutrophils and monocytes. Cell 1989, 59:305-312

48. Pitchford S, Momi S, Giannini S, Casali L, Spina D, Page C, Gresele P: Platelet P-selectin is required for pulmonary eosinophil and lymphocyte recruitment in a murine model of allergic inflammation. Blood 2005, 105:2074-2081

49. Evangelista V, Manarini S, Sideri R, Rotondo S, Martelli N, Piccoli A Totani L, Piccardoni P, Vestweber D, de Gaetano G, Cerletti C: Platelet/polymorphonuclear leukocyte interaction: $\mathrm{p}$-selectin triggers protein-tyrosine phosphorylation-dependent CD11b/CD18 adhesion: role of PSGL-1 as a signaling molecule. Blood 1999, 93:876-885

50. Blanks JE, Moll T, Eytner R, Vestweber D: Stimulation of P-selectin glycoprotein ligand-1 on mouse neutrophils activates beta 2-integrin mediated cell attachment to ICAM-1. Eur J Immunol 1998, 28:433-443

51. Akira S, Taga T, Kishimoto T: Interleukin-6 in biology and medicine. Adv Immunol 1993, 54:1-78

52. Longhurst CM, Jennings LK: Integrin-mediated signal transduction Cell Mol Life Sci 1998, 54:514-526

53. Kasper B, Brandt E, Bulfone-Paus S, Petersen F: Platelet factor 4 (PF-4)-induced neutrophil adhesion is controlled by src-kinases, whereas PF-4-mediated exocytosis requires the additional activation of p38 MAP kinase and phosphatidylinositol 3-kinase. Blood 2004, 103:1602-1610

54. Weyrich AS, Elstad MR, McEver RP, McIntyre TM, Moore KL, Morrissey $\mathrm{JH}$, Prescott SM, Zimmerman GA: Activated platelets signal chemokine synthesis by human monocytes. J Clin Invest 1996, 97:1525-1534

55. Burger PC, Wagner DD: Platelet P-selectin facilitates atherosclerotic lesion development. Blood 2003, 101:2661-2666

56. Schober A, Manka D, von Hundelshausen $P$, Huo $Y$, Hanrath $P$, Sarembock I, Ley K, Weber C: Deposition of platelet RANTES triggering monocyte recruitment requires P-selectin and is involved in neointima formation after arterial injury. Circulation 2002, 106:1523-1529

57. Kuebler W: Selectins revisited: the emerging role of platelets in inflammatory lung disease. J Clin Invest 2006, 116:3106-3108 